\title{
Cytogenetic Abnormalities and Their Impact on Treatment Outcome in Paediatric Acute Myeloid Leukaemia in Pakistan
}

\author{
Sumaira Khalil, Tariq Ghafoor, Tanzeela Farah and Awais Arshad \\ Department of Paediatric Oncology, Combined Military Hospital, Rawalpindi, Pakistan
}

\begin{abstract}
Objective: To determine the impact of cytogenetic abnormalities on the treatment outcome of paediatric acute myeloid leukaemia (AML) at a tertiary care facility of Pakistan.

Study Design: Retrospective Observational study.

Place and Duration of Study: Paediatric Oncology Ward, Combined Military Hospital, Rawalpindi, from January 2012 to September 2019.

Methodology: All registered cases of AML under 18 years of age, admitted to paediatric oncology ward in Combined Military Hospital, Rawalpindi, who had completed their treatment before $30^{\text {th }}$ September 2019 were included. Their demographic and clinical data including WBC counts, immunophenotyping, cytogenetic abnormalities and impact of cytogenetics on disease outcome was assessed. Data was analysed for descriptive statistics and association of proportions.

Results: Data of 138 cases of de novo AML including $90(65.2 \%)$ males and $48(34.8 \%)$ females were analysed. The mean age was $6.37 \pm 3.51$ years. Initial WBC of more than $50 \times 10^{9} / \mathrm{L}$ was seen in $43(31.2 \%)$ patients. The most common FAB subtype was $\mathrm{M}-2$ in 74 (53.6\%), followed by M-4 in 20 (14.5\%) cases. The majority of cases 81 (58.7\%) had normal cytogenetics followed by 42 (30.4\%) favourable and 15 (10.8\%) unfavourable abnormalities. Five-year overall survival was $82.4 \%, 56.5 \%$ and $55.6 \%$ for favourable, intermediate and unfavourable risk cytogenetics, respectively $(p=0.039)$. Disease-free survival was $82.4 \%, 51.6 \%$ and $44.4 \%$ for favourable, intermediate and unfavourable risk cytogenetics $(p=0.008)$.

Conclusions: Identification of cytogenetic aberrations at diagnosis will help in risk stratification and predicting prognosis in AML. This will further assist in improving treatment strategies for different cytogenetic risk groups.
\end{abstract}

Key Words: Paediatric acute myeloid leukaemia, Cytogenetics, Treatment outcome.

How to cite this article: Khalil S, Ghafoor T, Farah T, Arshad A. Cytogenetic Abnormalities and Their Impact on Treatment Outcome in Paediatric Acute Myeloid Leukaemia in Pakistan. J Coll Physicians Surg Pak 2020; 30(04):379-384. DOI: https://doi.org/10.29271/jcpsp.2020.04.379.

\section{INTRODUCTION}

Acute myeloid leukaemia (AML) comprises a heterogeneous group of disorders, initially recognised on the basis of morphology. French-American-British (FAB) AML classification system, though very useful in making the diagnosis of $A M L$ subtypes, it does not provide predictive prognostic information. ${ }^{1,2}$ The treatment outcome of AML mainly depends upon response to induction chemotherapy and subsequent intensification of treatment, according to the molecular and cytogenetic aberration. ${ }^{3}$ Cytogenetic analysis is helpful in diagnosis, disease monitoring, risk stratification for treatment of AML; and has prognostic significance. It has been incorporated in the World Health Organization (WHO) classification of tumors of the hematopoietic and lymphoid tissues since 2008 and was revised in 2016. 4.5

Pakistan is a low- and middle-income country (LMIC) and has very limited access to care for the vast majority of children with cancer.

Correspondence to: Dr. Sumaira Khalil, Department of

Paediatric Oncology, Combined Military Hospital,

Rawalpindi, Pakistan

E-mail:sumairakhalil@hotmail.com

Received: February 24, 2020; Revised: April 25, 2020;

Accepted: May 10, 2020

DOI: https://doi.org/10.29271/jcpsp.2020.04.379
Majority of health-care centres in Pakistan are not treating AML due to financial constraints, high disease-related and treatment-related morbidity and mortality resulting in limited data about this disease. ${ }^{6,7}$ Previous studies done on AML usually targets clinical and morphological pattern of disease. Few studies have been done in past on paediatric AML cytogenetics and data is limited. Cytogenetic aberrations associated with AML has prognostic significance, and are rarely discussed in this region. ${ }^{8}$ This study will help in identification of different cytogenetic aberrations associated with paediatric AML and how they affect the prognosis and disease outcome.

The aim of this study was to determine the impact of cytogenetic abnormalities on the treatment outcome of paediatric acute myeloid leukaemia (AML) at a tertiary care facility of Pakistan.

\section{METHODOLOGY}

This observational study was carried out at Paediatric Oncology Ward in Combined Military Hospital, Rawalpindi. The institutional review board and hospital ethical committee approved the study. Data of all newly diagnosed patients of childhood AML admitted in Paediatric Oncology Ward from $1^{\text {st }}$ January 2012 onwards and completed their treatment before $30^{\text {th }}$ September 2019 was collected retrospectively from patient's files kept in medical record of department and noted on patient's proforma. All newly diagnosed patients of $A M L$, both males and females, younger than 
18 years of age and had not received any prior cancer therapy, were included. Cases having acute promyelocytic leukaemia (APL), AML with Down Syndrome (AMLDS), therapy-related AML (t-AML), left treatment and without cytogenetic results were excluded.

Every patient had a detailed medical history and clinical examination. Diagnosis of AML was confirmed on the findings of peripheral blood, bone marrow morphology, flow cytometric immunophenotyping, molecular and cytogenetic analysis by standard techniques.

Diagnostic tests including cytogenetic analysis was performed on peripheral blood sample, if there was hyperleukocytosis (white cell count $>25 \times 10^{9} / \mathrm{L}$ ) and blast cells on peripheral blood and BMA (bone marrow aspiration) was performed when there was no evidence of hyperleukocytosis on peripheral blood. Chromosome studies were performed on trypsin G-banded chromosome preparations from 24-hour and 48-hour unstimulated cultures. Cytogenetic analysis was considered successful, if a clonal chromosomal abnormality was detected or a minimum of 20 metaphases were analysed. An abnormality was considered to be clonal when at least two metaphases had the same structural abnormality or the same additional chromosome, or when at least three metaphases had the same monosomy. If a clonal aberration was absent and 20 or more metaphases had a normal karyotype, the patient was considered to be cytogenetically normal.

Karyotypes were described according to the International System for Human Cytogenetic Nomenclature (ISCN) 2009. Complex karyotypes were defined as those with at least three acquired chromosomal aberrations in the absence of cytogenetic abnormalities listed under the WHO category of AML with recurrent genetic abnormalities. Cytogenetic abnormalities were divided into favourable, intermediate and unfavourable risk groups according to WHO 2016 update.

Chemotherapy was based on AML17 Paediatric version. During induction therapy, two courses of anthracycline based chemotherapy (Daunorubicin $50 \mathrm{mg} / \mathrm{m}^{2}$ on day 1,3 and 5 and cytarabine $100 \mathrm{mg} / \mathrm{m}^{2}$ twice daily) for 10 days in course 1 and 8 days in course 2 were given.

Post-remission treatment included two courses of high dose cytarabine ( $3000 \mathrm{mg} / \mathrm{m}^{2}$ twice daily on day 1, 3 and 5) chemotherapy as consolidation therapy. Patients showing partial response (BM Blasts 5-25\% and 50\% decrease of pre-treatment BM blasts) after induction chemotherapy received FLA-Ida (Fludarabine $30 \mathrm{mg} / \mathrm{m}^{2}$ daily on days 1-5, cytosine arabinoside 2000 $\mathrm{mg} / \mathrm{m} 2$ daily on days $1-5$ and idarubicin $10 \mathrm{mg} / \mathrm{m}^{2}$ on days $4,5 \& 6$ ) chemotherapy as consolidation therapy.

Treatment related mortality (TRM) was defined as any death occurring within 42 days of starting chemotherapy or any death after this period which is not due to relapse or refractory disease while patient is still on treatment. After induction chemotherapy remission status was assessed by repeating bone marrow aspiration when peripheral counts were recovered that is absolute neutrophil count (ANC) was $>1.0$ and platelets were $>100 x$ $10^{9} / \mathrm{L}$
During treatment, patients were admitted with febrile neutropenia and managed with broad spectrum intravenous antibiotics and supportive blood product transfusions.

After end of treatment, regular follow-up was done every month for first 6 months, 2-3 monthly for next 6 months, 4-6 monthly for next 1 year and 6 month after 2 years. At each follow-up visit patient was completely examined for evidence of extra-medullary disease and CBC (complete blood count) was done to look for any cytopenias. Disease relapse was defined as BM blasts $>5 \%$ or reappearance of blasts in blood after attaining $C R$.

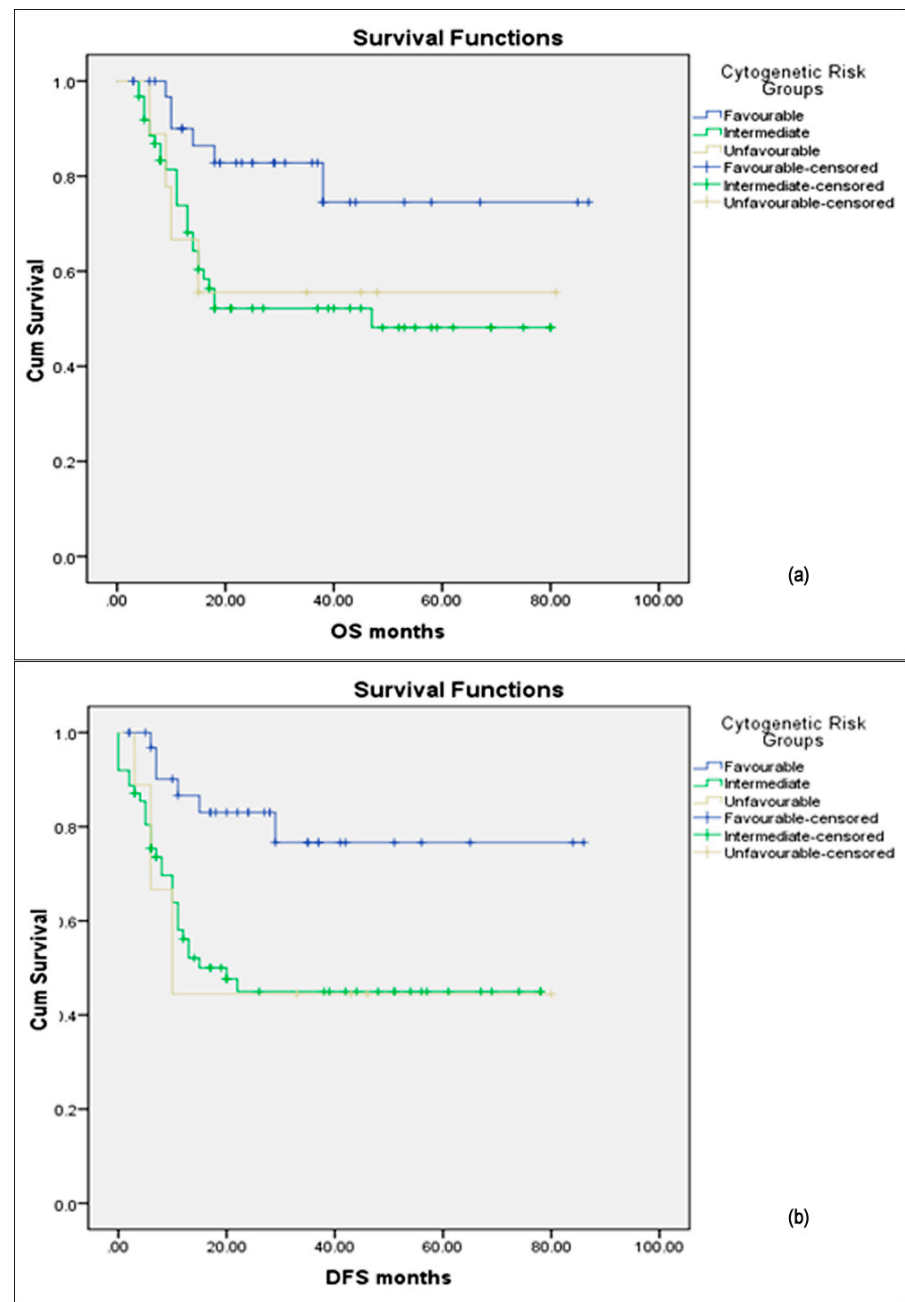

Figure 1: Survival curves of different cytogenetic risk groups in paediatric AML, showing significant favourable overall survival (OS); (a) and diseasefree survival (DFS); (b) in favourable, cytogenetic riskgroups.

Disease-free survival (DFS) was defined as the time from achievement of CR until relapse. Overall survival (OS) was defined as the time from the date of diagnosis till last follow-up or death from any cause. Complete remission (CR) was defined as bone marrow blasts less than $5 \%$ and evidence of regenerating normal hematopoietic cells.

Data was extracted from patients' files and recorded on preformed proforma regarding age, gender, haematological parameters like white blood cell count (WBC), haemoglobin $(\mathrm{Hb})$ and platelets, FAB classification, cytogenetic abnormalities, molecular gene-tics, treatment and follow-up details including remission status, relapse or death. 
Table I: Baseline patient characteristics and outcomes among different aml cytogenetic risk groups.

\begin{tabular}{|c|c|c|c|c|}
\hline & $\begin{array}{c}\text { Favourable cytogenetic } \\
\text { risk group } \\
n=42(30.4 \%)\end{array}$ & $\begin{array}{c}\text { Intermediate cytogenetic } \\
\text { risk group } \\
\mathbf{n = 8 1}(\mathbf{5 8 . 7 \% )}\end{array}$ & $\begin{array}{c}\text { Unfavourable } \\
\text { cytogenetic risk } \\
\text { group } \\
n=15(10.8 \%)\end{array}$ & p-value \\
\hline $\begin{array}{l}\text { Age groups } \\
<5 \text { years } \\
5-9 \text { years } \\
>9 \text { years }\end{array}$ & $\begin{array}{c}9(21.4 \%) \\
19(45.2 \%) \\
14(33.3 \%)\end{array}$ & $\begin{array}{c}33(40.7 \%) \\
34(42 \%) \\
14(17.3 \%)\end{array}$ & $\begin{array}{c}9(60 \%) \\
5(33.3 \%) \\
1(6.7 \%)\end{array}$ & 0.031 \\
\hline $\begin{array}{l}\text { Gender } \\
\text { Males } \\
\text { Females }\end{array}$ & $\begin{array}{l}28(66.7 \%) \\
14(33.3 \%)\end{array}$ & $\begin{array}{l}53(65.4 \%) \\
28(34.6 \%)\end{array}$ & $\begin{array}{l}9(60 \%) \\
6(40 \%)\end{array}$ & 0.896 \\
\hline $\begin{array}{l}\text { Hematological parameters } \\
\text { WBC }(\times 1000 / \mu \mathrm{L}) \\
<50 \\
>50 \\
\mathrm{Hb}(\mathrm{g} / \mathrm{dL}) \\
<7 \\
>7 \\
\text { Platelets }(\times 1000 / \mu \mathrm{L}) \\
<20 \\
>20\end{array}$ & $\begin{array}{c}33(78.6 \%) \\
9(21.4 \%) \\
39(92.9 \%) \\
3(7.1 \%) \\
19(45.2 \%) \\
23(54.8 \%)\end{array}$ & $\begin{array}{c}50(61.7 \%) \\
31(38.3 \%) \\
65(80.2) \\
16(19.8 \%) \\
22(27.2 \%) \\
59(72.8 \%)\end{array}$ & $\begin{array}{c}12(80 \%) \\
3(20 \%) \\
14(93.3 \%) \\
1(6.7 \%) \\
8(53.3 \%) \\
7(46.7 \%)\end{array}$ & 0.099 \\
\hline $\begin{array}{l}\text { Immunophenotypes } \\
\text { AML M0 } \\
\text { AML M1 } \\
\text { AML M2 } \\
\text { AML M4 } \\
\text { AML M5 } \\
\text { AML M6 } \\
\text { AML M7 } \\
\text { AML NOS }\end{array}$ & $\begin{array}{c}0 \\
1(2.4 \%) \\
35(83.3 \%) \\
6(14.3 \%) \\
0 \\
0 \\
0 \\
0\end{array}$ & $\begin{array}{c}3(3.7 \%) \\
14(17.2 \%) \\
33(40.7 \%) \\
14(17.3 \%) \\
4(4.9 \%) \\
0 \\
3(3.7 \%) \\
10(12.3 \%)\end{array}$ & $\begin{array}{c}3(20 \%) \\
1(6.7 \%) \\
6(40 \%) \\
0 \\
0 \\
3(20 \%) \\
0 \\
2(13.3 \%)\end{array}$ & $<0.001$ \\
\hline $\begin{array}{l}\text { Complete remission }(n=93) \\
\text { Disease relapse } \\
\text { Overall survival } \\
\text { Disease-free survival }\end{array}$ & $\begin{array}{l}32(34.4 \%) \\
6(17.6 \%) \\
28(82.4 \%) \\
28(82.4 \%)\end{array}$ & $\begin{array}{l}54(58.1 \%) \\
24(38.7 \%) \\
35(56.5 \%) \\
32(51.6 \%)\end{array}$ & $\begin{array}{l}7(7.5 \%) \\
5(55.5 \%) \\
5(55.6 \%) \\
4(44.4 \%)\end{array}$ & $\begin{array}{l}0.037 \\
0.039 \\
0.008\end{array}$ \\
\hline
\end{tabular}

Table II: Cytogenetic findings in different risk groups.

\begin{tabular}{|l|c|c|}
\hline Cytogenetics & Risk group & $\begin{array}{c}\text { Number of patients } \\
\text { (\%) }\end{array}$ \\
\hline $\begin{array}{l}\mathrm{t}(8,21)(\mathrm{q} 22: \mathrm{q} 22) / A M L I \\
\text { inv16/t(16,16)/CBFB MYH11 } \\
\text { NPM1 mutation }\end{array}$ & Favourable & $42(30.4 \%)$ \\
\hline Normal karyotypes & Intermediate & $81(58.7 \%)$ \\
\hline $\begin{array}{l}\text { Complex karyotypes } \\
\text { Monosomy } 7 \\
\begin{array}{l}\text { Trisomy } 8 \\
\mathrm{t}(16,21) / \text { FUS-ERG mutation }\end{array}\end{array}$ & Unfavourable & $15(10.8 \%)$ \\
\hline
\end{tabular}

All the collected data were electronically formalised and later analysed by using Microsoft Excel version 13 and SPSS version 21. Descriptive statistics were applied. Categorical data, i.e. qualitative variables were summarised as frequencies and percentages while mean and standard deviation were used to express quantitative variables. Different categorical variables were compared using Chi-square test and $p$-value of $<0.05$ was considered statistically significant. Five year DFS and OS were estimated by using the Kaplan-Meier method and Log rank tests were used to compare survival differences among groups.

\section{RESULTS}

During the study period, a total of 272 new cases of paediatric AML were registered. Fifty-two of them including 40 cases of APL, 2 cases who left during treatment, 4 cases with Down syndrome, and 6 cases still on treatment at the time of analysis, were excluded from the study in the first phase of evaluation. Out of the remaining 220 cases, samples for cytogenetics were sent for 150 cases (68.2\%). Cytogenetic results were not available in $12(8.0 \%)$ cases due to poor quality of chromosomes or insufficient number or absence of metaphases. This cohort of 138 cases with available cytogenetic results included $90(65.2 \%)$ males and $48(34.8 \%)$ females with the mean age of $6.37 \pm 3.51$ years. Initial WBC of more than $50 \times 10^{9} / \mathrm{L}$ was seen in $43(31.2 \%)$ patients. The mean hemoglobin was 7.62 $\pm 2.70 \mathrm{~g} / \mathrm{dl}$, and the mean platelets count was 57.75 $\pm 79.4710^{9} /$. The most common FAB subtype was $M-2$ in 74 (53.6\%), followed by $M-4$ in 20 (14.5\%) cases. Details of these baseline characteristics among different cytogenetic risk groups is shown in Table $\mathrm{I}$.

Normal karyotype was observed in 81 (58.7\%) cases and abnormal karyotype in 57 (41.3\%) cases. Eighty-one (58.7\%) patients had intermediate-risk (normal cytogenetic), 42 (30.4\%) favourable and 15 (10.8\%) unfavourable cytogenetic abnormalities. The most frequent cytogenetic abnormality was 
t $(8 ; 21) / A M L 1-E T O$ in 33 (24\%) followed by inv 16/t (16, 16)/CBFB MYH11 in 8 (5.8\%) patients; and complex karyotypes were identified in $12(8.7 \%)$ cases. Details of cytogenetic findings and their grouping into different risk groups is shown in Table II.

Favourable and intermediate cytogenetic were most commonly observed in children older than 5 years while unfavourable cytogenetic were observed in younger children. ( $p$ value 0.031 ). All the cytogenetic risk groups were equally affecting males and females and no significant association was observed in different cytogenetic risk groups and gender $(p=0.896$, Table I).

Treatment related mortality (TRM) during chemotherapy was $20(14.5 \%)$ in first, $9(6.5 \%)$ in second and $4(2.9 \%)$ in third course of chemotherapy. No patient died during the fourth and last chemotherapy course. After exclusion of the 33 TRM cases, data of remaining 105 cases was further analysed for disease outcome. Complete remission was achieved in 93 $(88.5 \%)$ patients. Out of them, 32 (34.4\%) patients had favourable, $54(58.1 \%)$ had intermediate and $7(7.5 \%)$ had unfavourable cytogenetics. Intermediate and unfavourable cytogenetics were significantly associated with disease relapse $(p=0.037)$. Twenty-four $(38.7 \%)$ patients from intermediate risk group and 5 (55.5\%) patients from unfavourable group presented with disease relapse while only $6(17.6 \%)$ patients from favourable group had relapse. Median follow-up duration was 18 months. Median duration of overall survival (OS) and disease-free survival (DFS) was 18 months and 15 months, respectively. Five-year overall survival (OS) and disease-free survival (DFS) was significantly different among different cytogenetic risk groups (Table I). Overall survival was $82.4 \%$, $56.5 \%$ and $55.6 \%$ for favourable, intermediate risk and unfavourable risk cytogenetic, respectively $(p=0.039)$. Disease-free survival was $82.4 \%, 51.6 \%$ and $44.4 \%$ for favourable, intermediate risk and unfavourable risk cytogenetic, respectively $(p=0.008)$. OS and DFS were significantly improved in patients with favourable cytogenetic risk groups as shown in Figure 1 (a) and (b).

\section{DISCUSSION}

This study describes the impact of cytogenetics on treatment outcome in childhood AML from Pakistan. Cytogenetics is an independent prognostic factor for determining clinical outcome in paediatric AML.

Chromosomal aberrations are identified in approximately $90 \%$ of patients with AML and WHO has also classified myeloid leukaemia into different subtypes based on these cytogenetic aberrations ${ }^{9}$. In this study, abnormal karyotypes were identified in 57 (41.3\%) patients and normal karyotype in 81 (58.7\%) patients. These findings are consistent with other studies done in Pakistan. ${ }^{10}$

Some studies have reported higher frequency of abnormal karyotypes as well; but overall range has been described between $35-45 \%$ which is slightly lower than the present findings. Patients with favourable cytogenetic including recurrent balanced translocations like $t(8,21)$, inv16/t $(16,16)$ comprises $34 \%-47 \%$ of paediatric cytogenetic aberrations and associated with good prognosis. In our study 42 (30.4\%) patients had favourable cytogenetic which is similar to reported incidence in literature. $9,10,11$

The most common favourable cytogenetic identified in our study was $t(8,21)$ in $33(24 \%)$ patients followed by inv $(16) / \mathrm{t}$ $(16,16)$ in $8(5.8 \%)$ patients. These findings are comparable to study presented by leukaemia research cytogenetic group where $t(8,21)$ is identified in $14 \%$ patients and inv $(16)$ in $7 \%$ patients. ${ }^{11}$ This translocation is reported previously in $20 \%$ of childhood AML and is considered to be the good prognostic marker. It is more commonly observed in children as compared to adults and this can be the reason for the increase incidence of favourable cytogenetic and good prognosis of childhood AML as compared to adult AML. This translocation is associated most commonly with FAB subtypes AML M1 and $M 2 .{ }^{12}$ Another study from India has also reported $t(8,21)$ in $26 \%$ patients and inv $(16) / \mathrm{t}(16,16)$ in $5 \% .{ }^{13}$ Studies done on western population has shown $t(8,21)$ and inv $(16) / t(16,16)$ in range of $7-16 \%$ and $5-8 \%$, respectively ${ }^{15}$.

Abnormal variants of $t(8,21)$ and other rare translocations that are reported to be associated with AML like t (6;9), t (9; $11), t(10,11)$, inv $(3) / t(3 ; 3)$ were not identified in our patients. In our study only one patient had NPM1 mutation with normal cytogenetic. This mutation is reported in $6-8 \%$ by childhood oncology group (COG) and AIEOP (Associazione Italliana di Ematologica e Oncologica Pediatrica). This is associated with normal karyotype in $20 \%$ of paediatric AML and has good prognosis. $^{14}$

This study showed increased frequency of favourable cytogenetics in older children as compared to children under 5 years of age. Similar findings have been reported previously where $t$ $(8 ; 21)$ and inv (16) occurred more frequently in older children and rarely in infants and associated with favourable outcome in older children. ${ }^{11.15,16}$

Unfavourable cytogenetics including complex karyotypes and other aberrations together comprises $10.8 \%$ of abnormal cytogenetic in our patients. Other studies have shown complex cytogenetic in $14.3 \%$ patients. ${ }^{17}$ Previously $10-20 \%$ of patients have been reported in complex cytogenetic group. ${ }^{18}$

Recently, 5 years survival in children with AML ranges between $50-60 \%$ and prognosis largely depends upon major cytogenetic subgroup. Favourable cytogenetic group is associated with better overall and disease-free survival. In our study, favourable cytogenetic group has overall survival (OS) $82.4 \%$. Previous studies have reported overall survival of $91 \%$ and $80 \%$ associated with $\mathrm{t}(8,21)$ and $87 \%$ and $81 \%$ for inv16/t $(16,16)$. These were the two major favourable cytogenetic aberrations in our study that were contributing good overall survival in patients. ${ }^{11,16}$

Overall survival rate of patients with normal karyotypes has been reported as 54\%, 42\% and 50\%, respectively. It was observed in $56.5 \%$ in this study, which is comparable to previous reports. Similarly, poor prognosis has been observed with unfavourable cytogenetics. In our study, this group 
includes monosomy 7, trisomy 8 and complex cytogenetics including unbalanced karyotypes with Del (16), 10q, 9p, hyperdiploidy, tetrahyperdiploidy etc. Complex cytogenetics are associated with OS of $40-45 \%$. Monosomy 7 has OS of $30-35 \%$ and trisomy 8 has OS 53\%. Other cytogenetics that are reported to be associated with unfavourable prognosis are inv3, monosomy 5 , del $(5 q)$, del $(7 q), t(3 ; 5), t(6 ; 9)$ and $t(9,11)$; but these were not identified in our patients. ${ }^{16,19-21}$

In this study, patients with favourable cytogenetic had disease-free survival of $82.4 \%$. A 10 -year disease-free survival (DFS) reported previously for favourable cytogenetic is $70-80 \%$ and for complex karyotypes, it is reported as $48 \%$. Complete remission (CR) in literature has been reported as 89\%; and in this study, it was $88.5 \%$. In favourable cytogenetic group $94 \%$ patients achieved CR after induction chemotherapy. CR after induction in previous studies have been reported between $70-80 \%$. Other studies reported $80-90 \%$ CR in favourable groups, $70-80 \%$ in the intermediate groups, and $50-60 \%$ in unfavourable risk groups. ${ }^{16,21,22}$

The present study has shown good OS, DFS and CR; and the results are comparable to studies done in other parts of world. In our country with resource limiting settings and inadequate medical facilities, cytogenetic/molecular studies are not done as routine diagnostic workup. This study has provided significant information on cytogenetic findings in our children with AML and its impact on outcome of disease. This study will provide a guide to other practitioners in predicting outcome of disease and improving treatment strategies for AML in our region.

\section{CONCLUSION}

Identification of cytogenetic abnormalities should be a part of routine diagnostic workup for AML. It will assist in risk strati-fication and predicting the survival associated with different cytogenetic risk groups. This will further help in future to modify treatment modalities and introduce novel therapeutic agents for complex and other unfavourable cytogenetics.

\section{ETHICAL APPROVAL:}

Institutional Review Board/ Ethical committee approval was obtained prior to initiation of study.

\section{PATIENTS' CONSENT:}

Patients consent was not applicable as it was a retrospective study.

\section{CONFLICT OF INTEREST:}

Authors declared no conflict of interest.

\section{AUTHORS' CONTRIBUTION:}

SK: Conception and study design, literature search, drafting the work and manuscript writing.

TG: Data collection, statistical analysis and interpretation of results. Critical analysis of content and final approval of study. TF, AA: Review of literature and manuscript proof reading.
1. Bennett JM, Catovsky D, Daniel MT, Flandrin G, Galton DA, Gralnick HR, et al. Proposals for the classification of the acute leukaemias. French-American-British (FAB) co-operative group. Br J Haematol 1976; 33:451-8.

2. Wang ML, Bailey NG. Acute myeloid leukemia genetics: risk stratification and implications for therapy. Arch Pathol Lab Med 2015; 139:1215-23.

3. de Rooij J, Zwaan C, van den Heuvel-Eibrink M. Pediatric AML: From biology to clinical management. J Clin Med 2015; 4:127-49.

4. Arber DA, Stein AS, Carter NH, Ikle D, Forman SJ, Slovak ML. Prognostic impact of acute myeloid leukemia classification. Importance of detection of recurring cytogenetic abnormalities and multilineage dysplasia on survival. Am J Clin Pathol 2003; 119:672-80.

5. Arber DA, Orazi A, Hasserjian R, Thiele J, Borowitz MJ, Le Beau $M M$, et al. The 2016 revision to the World Health Organization classification of myeloid neoplasms and acute leukemia. Blood 2016; 127:2391-405.

6. Kurji Z, Premani ZS, Mithani Y. Analysis of the health care system of Pakistan: Lessons learnt and way forward. J Ayub Med Coll Abbottabad 2016; 28:601-4.

7. Gupta S, Rivera-Luna R, Ribeiro RC, Howard SC. Pediatric oncology as the next global child health priority: The need for national childhood cancer strategies in low- and middle-income countries. PLoS Med 2014; 11:e1001656.

8. Tyagi A, Pramanik R, Chaudhary S, Chopra A, Bakhshi S. Cytogenetic profiles of 472 Indian children with acute myeloid leukemia. Indian Pediatr 2018; 55:469-73.

9. Gupta M, Mahapatra M, Saxena R. Cytogenetics' impact on the prognosis of acute myeloid leukemia. J Lab Physicians 2019; 11:133-7.

10. Shaikh MS, Ahmed ZA, Shaikh MU. Distribution of chromo-somal abnormalities commonly observed in adult acute myeloid leukemia in Pakistan as predictors of prognosis. Asian Pac J Cancer Prev 2018; 19:1903-6.

11. Harrison CJ, Hills RK, Moorman AV., Grimwade DJ, Hann I, Webb DKH, et al. Cytogenetics of childhood acute myeloid leukemia: United Kingdom medical research council treatment trials AML 10 and 12. J Clin Oncol 2010; 28:2674-81.

12. Reikvam H, Hatfield KJ, Kittang AO, Hovland R, Bruserud O. Acute myeloid leukemia with the $t(8 ; 21)$ translocation: Clinical consequences and biological implications. J Biomed Biotechnol 2011; 2011:104631.

13. Amare PS, Jain $\mathrm{H}$, Kabre $\mathrm{S}$, Deshpande $\mathrm{Y}$, Pawar $\mathrm{P}$, Banavali $\mathrm{S}$, et al. Cytogenetic profile in 7,209 Indian patients with de novo acute leukemia: A single centre study from India. J Cancer Ther 2016; 7:530-44.

14. Hollink I, Zwaan C, Zimmermann M. Favorable prognostic impact of NPM1 gene mutations in childhood acute myeloid leukemia, with emphasis on cytogenetically normal AML. Leukemia 2008; 23:262-70.

15. Manola KN. Cytogenetics of pediatric acute myeloid leukemia. Eur J Haematol 2009; 83:391-405.

16. Betts DR, Ammann RA, Hirt A. The prognostic significance of cytogenetic aberrations in childhood acute myeloid leukaemia: A study of the Swiss paediatric oncology group (SPOG). Eur J Haematol 2007; 78:468-76.

17. Meng CY, Noor PJ, Ismail A, Ahid MF, Zakaria Z. Cytogenetic profile of de novo acute myeloid leukemia patients in Malaysia. Int J

\section{REFERENCES}


Biomed Sci 2013; 9:26-32.

18. Schoch C, Haferlach T. Cytogenetics in acute myeloid leukemia. Curr Oncol Rep 2002; 4:390-7.

19. Grimwade D, Walker H, Harrison G. The predictive value of hierarchical cytogenetic classification in older adults with acute myeloid leukemia (AML): analysis of 1,065 patients entered into the United Kingdom medical research council AML11 trial. Blood 2001; 98:1312-20.

20. Ravindranath $Y$, Chang $M$, Steuber CP. Pediatric oncology group (POG) studies of acute myeloid leukemia (AML): A review of four consecutive childhood AML trials conducted between 1981 and 2000. Leukemia 2005; 19:2101-16.

21. Lie SO, Abrahamsson J, Clausen N. Treatment stratification based on initial in vivo response in acute myeloid leukaemia in children without Down's syndrome: Results of NOPHO-AML trials. Br J Haematol 2003; 122:217-25.

22. Harani MS, Adil SN, Kakepeto GN, Khijli Z, Shaikh M, Khurshid $\mathrm{MU}$, et al. Significance of cytogenetic abnormalities in acute myeloid leukemia. Jf Pak Med Assoc 2006; 56:9-13. 